\title{
THE ENFOLDING OF ONE ORGANISATION INTO ANOTHER: A CONFLICT OF IDENTITY AND A QUEST FOR MEANING
}

\author{
Kasebwe Timothee Luc Kabongo \\ Department of Religion Studies \\ University of Pretoria
}

\begin{abstract}
This research investigates the enfolding of InnerCHANGE into Novo. These are two organisations with distinct identities that joined forces in 1985, and InnerCHANGE became one of the collectives under Novo. When they came together, they agreed to prioritise the evangelistic mandate of the church. They fleshed out their agreement into a hybrid model encompassing four areas of growth. These areas of growth are quantitative, qualitative, organic and incarnational. When these have been put to good use, they have contributed positively to their common purpose. However, this hybrid model seems to be a compromise that neither of these organisations fully adhere to. They do not focus equally on the four areas of growth. Sometimes an area of growth is portrayed as the best expression of their common purpose at the expense of others, which has stirred up some tensions in the organisations. This article reflects on the fruitfulness of the cohabitation of Novo and InnerCHANGE, and how this plays out on the local team level of InnerCHANGE South Africa. It also engages the existing tensions around the agreed upon four areas of growth to bring reconciliation and draw wisdom from it. The article is structured around how the cohabitation between Novo and InnerCHANGE started, cross-fertilisation, interaction with internal tensions and how the four areas of growth play out at a local InnerCHANGE level. It concludes that an intentional implementation of the four areas of growth by both Novo and InnerCHANGE could generate much wisdom and effectiveness in terms of their common purpose.
\end{abstract}

Keywords: Cohabitation; Cross-fertilisation; Discipleship; Growth; Tension

\section{Introduction}

This study investigates the enfolding of InnerCHANGE into Novo. These two organisations with distinct identities joined forces in 1985, with InnerCHANGE becoming one of the collectives of Novo. Novo is "a band of creative missionaries sent to multiply movements of the gospel and mobilize the church for mission around the world" (novo.org 2020). Novo was founded in 1980 in the United States of America (USA) by a group of leaders from the Christian organisation Navigators, who felt a calling to focus on discipleship and the church growth movement (Metcalf 1989:1). Its vision and mission prioritise the evangelistic mandate of the church. Novo has missionaries in 90 countries around the world. 
InnerCHANGE was founded by John Hayes in 1984. It is a Christian order among the poor. It focuses on discipleship and inside-out community development in areas of poverty. Christian orders value communal life and live by "a common covenant and/or common commitments" (Barker and Hayes 2002:134-135). It has been functioning as one of the Novo collectives since 1985 and currently has 18 teams in five continents around the world. Therefore, every InnerCHANGE member is also a Novo staff member or affiliate.

I joined one of Novo's collectives in 2004 and moved to InnerCHANGE in 2008 (to date). In this research, I engage with the cohabitation of Novo and InnerCHANGE because this sometimes causes tension and conflict in terms of priorities. I have been wondering how to synergise these two identities. What wisdom can be drawn from two apparently conflicting identities? I serve in the context of South Africa. This case study research is a quest for meaning and wisdom. I am aware that when InnerCHANGE enfolded into Novo, the two organisations agreed on a hybrid model of four areas of growth that were meant to strengthen the implementation of their common purpose. However, both organisations seem to prioritise some areas of growth at the expense of others. And there has at times been an implicit expectation that these preferred areas of growth be adopted by the other party. This creates tensions. This article reflects on these tensions as well as on the fruitfulness of the affiliation of Novo and InnerCHANGE in a quest for wisdom with regards to the running of a team such as InnerCHANGE South Africa. It explores how the enfolding of Novo and InnerCHANGE began, the gains of their affiliation, followed by an engagement with areas of tension, and ends with a reflection focused on InnerCHANGE South Africa.

\section{How it all started}

The coming together of Novo and InnerCHANGE started in 1984 as a friendship between the president of Novo, Samuel Metcalf, and the founder of InnerCHANGE, John Hayes, in California, USA. Hayes was a member of a weekly discipleship group for single men led by Samuel Metcalf. God brought their hearts and minds together and they decided to bring their organisations together into one fold. These two organisations anchored their cohabitation in four aspirational areas of growth (Metcalf 1989:99-100) namely:

Quantitative growth. Here the focus is on the conversion of as many people as possible to become followers of Jesus. This focus is linked to the implementation of the great commission found in Matt. 28:18-20. Novo/InnerCHANGE are equipped to prioritise the human redemption that comes with knowing and following Jesus as saviour. Already in 1985 Novo/InnerCHANGE envisioned serving in different contexts around the world and the common purpose of all their staff was framed around discipleship leading to the increase in numbers of believers.

Qualitative growth. This area concentrates on the vertical growth of followers of Jesus, growing close to Him in their obedience and their decision to adopt a Christ-like lifestyle. This area is connected to the first part of Mark 1:17, where Jesus invites his first disciples to follow and journey with Him so they can learn from Him. Personal and communal discipleship aiming to be Christ-like is the goal of this growth.

Organic growth. The focus here is for individuals and teams to strive to be culturally relevant, to structure themselves in ways that enable them to care well for their co- 
workers and the people they disciple, and to be tangible signs of hope in their contexts. This area envisions what a functional team could look like, particularly in cross-cultural and international contexts. In such contexts, staff are encouraged to catalyse new, meaningful and relevant expressions of the body of Christ. These expressions should preferably be led by local people. In contexts outside the USA, these teams need to be registered as legal entities for the sustainability of the ministry. Such an approach would also make a team organisationally capable of facilitating the above-mentioned two types of growth.

Incarnational growth. The focus here is on teams striving to identify with their contexts as holistically as possible. This area is related to John 3:16, where love is connected to the desire and passion to live in a certain way in order to identify with the people of a certain context. Such identification is a way to be salt and light in the world as tangible conduits of God's love and compassion in a particular context.

These four areas were a compromise acknowledging existing areas of strength and willingness to be complemented in other growth areas. However, from the beginning, the strongest connection between Novo and InnerCHANGE was their focus on discipleship, which is the first growth area. Novo showed strong qualitative growth. Its motto is "empowering leaders worldwide" and its staff focused on equipping and strengthening the body of Christ. The outcome of these efforts led to vertical growth of Christians and the renewal of local churches. So quantitative growth was not as strong as qualitative growth, which emphasises the strengthening and renewal of the body of Christ. This played out as expansion where North Americans were sent to different contexts around the world. In these international contexts, many teams remained $100 \%$ North American and many of their administrative needs were catered for by Novo in the USA. However, since 2011 Novo has been proclaiming quantitative growth as its main focus, seemingly emphasising it more strongly than other areas. Novo uses different resources to equip staff for evangelism and discipleship. One of the most effective resources it uses, is Discovery Bible Studies (DBS). Metcalf (2019:17) describes it as a "non-threatening way for people who are far from God to discover first-hand what the Bible says about God, people, and what it means to follow Jesus". DBS can be presented or completed anywhere, also orally through storytelling. DBS has been a catalyst for both the multiplication of believers and the formation of missional teams.

InnerCHANGE, on the other hand, was already serving in a community of poverty as an incarnational ministry. Its staff (all North Americans at the time) were already learning Spanish and Khmer because they were living in a neighbourhood that was predominantly composed of migrants from Latin America and Cambodia. A few organic teams led by neighbours were already flourishing in the community. InnerCHANGE enfolded into Novo with good knowledge capital in terms of organic and incarnational growth.

It appeared that Novo and InnerCHANGE needed each other for improvement and to add depth to their purpose. The symbiotic relationship between these four growth areas that were foundational in their coming together, were intended to nurture good news agents. This article understands the latter as followers of Jesus who value the multiplication of other followers while striving to grow in their intimacy and obedience to Jesus. These agents catalyse meaningful, contextual and relevant expressions of the body of Christ and immerse themselves in their contexts of ministry and life. Such an 
immersion aims to nurture agency in community development as a tangible expression of the good news of the gospel. The aim of this compromise was cross-fertilisation for a smooth nurturing of good news agents in every context staff live in.

\section{Cross-fertilisation}

Novo and InnerCHANGE strengthen one another in the pursuit of their common purpose. The president of Novo points this out by saying: "InnerCHANGE has influenced [Novo] in the direction of biblical holism" in balancing word and deed (Metcalf 2018:33-34). InnerCHANGE's understanding of quantitative growth encompasses both proclamation and deed aspects. Its founder, John Hayes (2006:240), says that the organisation aims to "express the Good News in both word and works. Both are necessary and inseparable components for evangelism. Winter (1974:13) concurs with this understanding when he postulates that "evangelism and socio-political involvement are both parts of our Christian duty". It seems that in Africa a church is needed that is proactive in socio-political involvement so that quality of life can be improved. The church not only needs to be involved but also needs to develop good news agents who can be involved. Katongole (2011:1) remarks that "Christianity continues to grow and thrive in Africa, but so too grow the realities of poverty, tribalism, corruption, violence, and civil wars". These social maladies undermine the description of the gospel as good news. Therefore, the church is challenged to participate in eradicating these social maladies through practical engagement. This could help invent "a new future in Africa"(Katongole 2011:23).

Novo's emphasis on quantitative and qualitative growth is a great resource for InnerCHANGE. Intentionality in quantitative growth allows InnerCHANGE to raise human capacity for ministry in communities of poverty that need community development. Intentionality in qualitative growth allows the nurturing and equipping of leaders who disciple others with multiplication as an outcome. Both quantitative and qualitative growth add to the existing strengths in organic and incarnational growth, which have made it possible for InnerCHANGE to have and sustain teams in 14 countries around the world. In many of these countries, Novo staff from other collectives have been critical partners in the launching and resourcing of InnerCHANGE teams. From the beginning of this cohabitation, InnerCHANGE has been benefitting administratively from support from Novo. InnerCHANGE has never been registered as a legal organisation in the USA. Most of its administrative support is dealt with by Novo. This cohabitation also had a positive impact on vision.

\section{Deepening of the sense of vision}

InnerCHANGE uses the action-reflection approach as a framework for its operations. Some Novo teams have adopted this approach which has brought proclamation and deed in close conversation in their ministries. As a gospel movement, Novo has been able to articulate its mission in a way that takes into consideration the four areas of growth. Metcalf (2019:8) describes a gospel movement as:

When the good news of Jesus spreads contagiously through a network of social relationships whereby many people become committed followers of Jesus, and 
groups of these disciples rapidly multiply. These movements transform cultures and have the potential to radically impact whole towns, cities, and nations.

This gospel movement has five components (Metcalf 2019:12-26):

a) Activating prayer. Fuder (2014:15) postulates that "prayer is foundational to any ministry initiative". Therefore, before we initiate anything, "we seek, individually and corporately, God's direction and leading" through prayer (Fuder 2014:15).

b) Engaging culture. One of the missions of the church is to be a tangible sign of the good news of the gospel in a particular context. Pillay (2017:1) points out that "throughout the ages, the church of Jesus Christ has normally understood the transformation of society to be an essential part of its mission task".

c) Making disciples. This is an intentional invitation to people to join the family of followers of Jesus as well as deepening the believers' obedience and dependence on Jesus.

d) Growing leaders. This refers to catalysing the development of followers of Jesus who will influence other people to follow Jesus so that the good news of the gospel can be heard, seen and experienced.

e) Forming churches. A direct outcome of disciple-making is the formation of contextual expressions of the body of Christ.

These five components of a gospel movement have been a creative way to capture the four areas of growth that all Novo/InnerCHANGE teams should be primarily concerned with. The reality seems to be that Novo and InnerCHANGE emphasise particular components of a gospel movement connected to their traditional strong areas of growth at the expense of others. This departure from the hybrid model of four areas of growth sometimes creates conflict and confusion about their common purpose. The president of Novo is aware of some of these conflicts. He points out that some InnerCHANGE members have tried to influence Novo "into their own image... This is particularly true for those with strong prophetic gifts" (Metcalf 1989:91). Grigg (1984:84) advises people involved in incarnational ministry such as InnerCHANGE to not judge all ministers by the "rigid structures" required for their sustained presence in communities of poverty. These conflicts within Novo (InnerCHANGE being one of the collectives) play out as a desire to assimilate one identity into the other. Therefore, the two organisations need to engage these conflicts to bring reconciliation and gain wisdom in this cohabitation.

\section{Interaction with internal conflicts}

Conflicts are unavoidable in any human interaction. Oppenshaw, Nel and Louw (2018:1) stress that conflicts are bound to occur in a mission organisation, but need "to be understood and handled theologically". Since Novo staff come from a diversity of backgrounds, different interpretations of the agreed-upon four areas of growth can be expected, which is "a breeding ground for conflict" (Nyiawung and Van Eck 2013:1). The manner in which conflict is addressed and resolved, can weaken or strengthen an organisation. Pali (2018:9) posits that the goal of conflict resolution is to promote harmony and peace. Oppenshaw, Nel and Louw (2018:2) define conflict as "an interactive process manifested on the incompatibility, disagreement, or dissonance 
within or between social entities such as individuals, a group or organisation". It drains energy, yet it is a necessary evil "because it elicits different points of view, clears the air, and makes it possible to resolve extraordinarily complex issues", leading to reconciliation (Osterhous et al. 2005:14).

We see such an example in the Council of Jerusalem in Acts 15:1-35 which included disciples of Jesus with different views about how non-Jewish converts were to be inducted in the community of believers. They reconciled their differences, which paved the way for the smooth internationalisation of Christianity.

This article reflects on the areas of conflict between Novo and InnerCHANGE in order to draw meaning and wisdom from them. The areas of conflict relate to the theology of place and multiplication, the understanding of the sustainability of a team, a functional team, and methodology of service and formation.

\section{Tension around the theology of place and multiplication}

One of the tensions is concerned with the interpretation of a gospel movement and incarnational ministry. This tension can be located in the quantitative and qualitative growth areas. On the one hand, Novo stresses expansion and rapid multiplication, which can sometimes result in a lack of depth and fragility of teams. On the other hand, InnerCHANGE emphasises incarnational ministry and can sometimes be guilty of focusing its efforts in one neighbourhood for many years, not feeling the urge to expand and multiply to other contexts. At times the opposing groups each feels their strategy is the best. Wisdom is probably in the middle. The way in which the $1^{\text {st }}$ century church operated could be helpful here. It reminds us of a church with the aim to both multiply in order to reach out to the whole world and be rooted in neighbourhoods so that the good news of the gospel can be seen and experienced (Pillay 2017). Therefore, a theology of place that intends to be a meaningful and tangible sign of love in a context, should also aim to multiply into different contexts. Such a theology would enable InnerCHANGE as a missional order to prioritise quantitative growth, which would raise its capacity to participate in improving the quality of life in communities of poverty. Such a theology would also equip other Novo collectives to prioritise ministry of deeds alongside quantitative growth. Brueggemann (2002:3-4) says that "rootlessness and not meaninglessness" may be the reason behind a successful or unsuccessful gospel movement.

\section{Sustainability of a team}

There has been tension about the definition of a sustainable team in terms of demographics. This tension is connected to organic growth. Many Novo teams serving cross-culturally seem to equate sustainability with monocultural teams. Hayes and Penate-Aceves (2010:145), who are InnerCHANGE members with a lot of cross-cultural experience, prefer multicultural teams because they seem to show more "grace than teams of people from the same culture". Additionally, "diverse communities are often marked by natural respect for and attention to observation" (Hayes and Penate-Aceves (2010:145). Monocultural mission teams serving cross-culturally may implicitly communicate some sort of ethnocentrism which may unintentionally exclude the host community from participating in the shaping of an organisation. It may also make it 
difficult for minorities in the context of the USA to join the organisation, which may endanger the vision of a global gospel movement.

I believe that multicultural teams are a sign of hope that brings together diversity and inclusiveness, which are needed in our world that seems to thrive on individualism and discrimination. Multicultural teams are kingdom-like because they are a representation of God's design for creation. One of the ways InnerCHANGE is fostering multicultural teams, is through the development of local leaders. InnerCHANGE is still predominantly American in terms of its membership. The development of local leaders has allowed InnerCHANGE to build capacity from within as well as catalysing organic expressions of the church. The investment in local leadership is one of the ways in which InnerCHANGE foresees sustainability that will outlive its founder as well as many team leaders who relocated to their current contexts to do InnerCHANGE work. I have seen teams within Novo and InnerCHANGE disintegrate as soon as the founder retired and felt called to move back to the USA.

The nurturing of local leadership would also challenge any messiah complex some missionaries may have. Kelsey (2017:155) understands a messiah complex as "a state of mind in which an individual holds a belief that they are the only person capable of assisting others". Such a state of mind atrophies quantitative and organic growths of an organisation. It is a danger to the sustainability of a gospel movement or any organisation that intends a long-lasting legacy. Perkins (1993:32-33) encourages indigenous leadership development because it develops ordinary people to take responsibility "for their own lives". Such leaders are challenged to focus on what it means to be students of Jesus who transcend societal divisions such as denominationalism, racism, tribalism and other forms of discrimination against others in order to become people who focus on the common good and life-affirming actions.

Monocultural teams may sustain individuals who need a regular space that is familiar to their culture of origin. It, however, defies the characteristics of a kingdom-like community, which is supposed to be diverse culturally, generationally and gender-wise.

\section{Tension about understanding a functional team}

With the exception of InnerCHANGE, Novo teams seem to shape their understanding of teams on task orientation or location in the same context. This tension is connected to qualitative growth. In these Novo teams, there is no expectation of team members to become a family of families on missions. In contrast to this, InnerCHANGE builds missional families that include all the families of members and some neighbours. As an order, InnerCHANGE members have a common way of life. They make seven commitments: to community, celebration, humility, prayer, purity, service and simplicity. Hayes and Penate-Aceves (2010:141-142) say that these commitments make it possible for InnerCHANGE members to "cultivate friendships with people [they] might not choose ordinarily". Such friendship requires everyone involved to make an adjustment which fosters grace, flexibility and other-centredness, which are critical in ministry. InnerCHANGE's identity is also preserved through the collective memory of its members. Hayes (2006:236) states that when InnerCHANGE is present and attentive to its history, it offers the "testimony of God's faithfulness to new generations of members as a dowry", an inspirational resource well remembered in order to provide wisdom for current and future realities. The communal life is also enriched by the 
diversity of artistic gifts members bring with them when they join. Hayes (2006:238239) thinks that it is "perhaps because God seems to form His people by forming the whole person: the right brain in concert with the left, the artists and engineers working together". The diversity is a constant reminder of the kingdom of God which is harmoniously diverse.

This missional commitment to one another in InnerCHANGE is also sometimes a liability. Hayes and Penate-Aceves (2010:145-146) point out that "most people come to the community with higher expectations for it than aptitude to express it". Therefore, a lot of energy, time and resources could be dedicated to building and sustaining an InnerCHANGE team at the expense of being involved in ministry outside the team. When people join InnerCHANGE, they are expected to be on a mission with others, which means more time should be spent serving neighbours and discipling them. However, some members spend a lot of time within their team at the expense of their neighbourhood ministry. All Novo collectives have challenged InnerCHANGE on many platforms to be intentional about striking a healthy balance between their contemplative life (building intimacy with God), their communal life and mission as part of a gospel movement.

\section{Tension around the methodology of service}

This tension is connected to organic growth. There seems to be a culture of "desktop or laptop expertise" within Novo that InnerCHANGE resists. This culture is a wellaccepted corporate culture all over the world. There have been instances where Novo staff postured as experts in disciple-making, for example, based on expertise acquired through boardroom training in ivory tower settings. They, therefore, trained people to do things of which they themselves had no personal experience. InnerCHANGE believes in "leading by doing" (Hayes 2006:182). The context of Africa, in particular, longs for leaders who walk the talk. The church could model this if it hopes to be an effective participant in the building of society. InnerCHANGE is learning to walk the talk in partnership with local communities in which teams catalyse the nurturing and development of local leaders. Such an approach has the potential to empower local community members as agents of the kind of society they would like to become. Also, the model of "desktop or laptop expertise" can be disempowering to communities of poverty because it reinforces the general belief that "know-how" comes from outside local communities and they should be eternal recipients of that expertise. InnerCHANGE is exploring the building of learning communities that include neighbours to foster a mutual learning culture as we attempt to be relevant participants in community building. In these gatherings, we invite "people called to love God and their neighbours. As such they try to participate in God's ongoing involvement in moving towards an anticipated future reality", which we hope is a hopeful one (Hendriks 2010:284). We are learning to believe that what we are doing, can make a difference in the world around us. Hence, we keep on serving and learning from our actions. Kraybill (1990:146) encourages us on this journey when he says: "It is easy to do nothing because we fear our small act won't count... However, when several million other people act the same way, the corporate consequences of our behaviour are" felt and seen. 


\section{Formation}

The InnerCHANGE formation model has also been a cause of tension in Novo. This tension is connected to qualitative growth. The formation model has been criticised as overly focused on communal life and ministry of deeds at the expense of quantitative growth. There have been incidents of InnerCHANGE teams functioning for a whole year without leading someone to follow Jesus. InnerCHANGE's focus on the ministry of deeds is sometimes at the expense of discipleship. This criticism exposes possible imbalances in the InnerCHANGE formation framework. The ideal framework would be a balance between contemplative life, communal life and mission (discipleship and community development work). This criticism could challenge InnerCHANGE to adopt a comprehensive approach (the ideal framework) to its ministry and the hybrid model of growth areas could be foundational. Incarnational ministry like the one InnerCHANGE lives by, is often understood as the ministry of presence. I understand it as a combination of the ministry of presence which includes discipleship, practical participation in building a society, and involvement of neighbours as partners.

InnerCHANGE has also pointed out the reality of many Novo staff leaving the field prematurely or burning out due to lack of a healthy communal life. Attention to the four areas of growth and a commitment to implementing them would resolve the matters that these criticisms raise. InnerCHANGE South Africa is learning to pay attention to these areas of growth

\section{InnerCHANGE South Africa and the four areas of growth}

The commitment to pay attention to the four areas of growth and incorporate them in how InnerCHANGE South Africa functions, started with the team design of a vision statement, which is:

InnerCHANGE South Africa exists to incarnationally live and serve among the poor in order for our communities to be transformed and disciples of Jesus to be made. We want to follow Jesus whole-heartedly, and collaborate with Him and with our neighbours to see movements of God's Kingdom in [our context] and beyond.

The first sentence of the vision captures the team's desire to deepen its contextual identification, its commitment to participate in transformational work (incarnational growth) and to raise capacity for the kingdom of God (quantitative growth). The second sentence expresses a desire to grow in intimacy with God (qualitative growth) and partner with neighbours to catalyse a gospel movement (organic growth). The team serves in different townships of the city of Pretoria. In these contexts, it serves communities through practical ministries such as after school tutoring, sport and healthcare. These are some of the ways it is learning "to promote the welfare" of these contexts (Winter 1994:200f.). Pillay (2017:2) stresses that "the world is not so much interested in what we believe today but in what the church is doing to transform society so that justice and peace may prevail". The ministries InnerCHANGE South Africa runs, are led by local leaders. These ministries are also platforms for discipleship.

This approach is still work in progress. The majority of time and resources is still spent on running service projects and equipping local leaders. The team would like to see quantitative growth that is proportional to the time investment in other areas. In the 
team context, quantitative growth is more about the nurturing of good news agents than conversion. The context is culturally Christianised and teamwork has mostly been focused on helping people be conduits of the gospel principles in their day-to-day life. People have also been converted and the team journeys with new converts with the hope of nurturing them as good news agents. The equipping of local leaders has resulted in many organic groups of servant leaders. Some of these teams disintegrated a few months after they started. This reality points to a formation gap that the team needs to address in order to build sustainable organic teams. In some instances, new organic teams have duplicated ministries offered by other organisations in a particular context. This points to the need to survey and read a new context comprehensively before starting a ministry initiative. The team goal in starting new initiatives, is to fill a gap, complement existing ministries in a context, or partner with like-minded organisations.

\section{Conclusion}

This case study reflected on the enfolding of InnerCHANGE into Novo. It pointed out how a personal relationship between Samuel Metcalf and John Hayes led to these two organisations joining forces. This affiliation was founded on a hybrid model of four areas of growth. The implementation of these areas of growth has allowed cross-fertilisation between these organisations. However, there has also been much tension about the implementation of these areas because Novo and InnerCHANGE seem to emphasise different areas of growth at the expense of others. Sometimes this emphasis manifests as a self-righteous sentiment that expects the other party to prioritise the same thing. This reality has led to conflict about a theology of place and multiplication, the sustainability of a team, what a functional team is, and a methodology of service and formation. These areas of conflict could be sources of wisdom because they all seem to bring Novo and InnerCHANGE back to an intentional and balanced implementation of the four areas of growth they agreed on when their relationship started. InnerCHANGE South Africa is learning to take into consideration the four areas of growth as it serves township communities. Its desire for a balanced approach is still work in progress.

\section{BIBLIOGRAPHY}

Barker, A. and Hayes, J. 2002. Sub-merge. Living deep in a shallow world. Springvale: Go alliance.

Brueggemann, W. 2002. The land: Place as gift, promise, and challenge in Biblical faith. $2^{\text {nd }}$ ed. Minneapolis: Fortress Press.

Fuder, J. 2014. Neighborhood mapping. How to make your church invaluable to the community. Chicago: Moody publishers.

Grigg, V. 1984. Companion to the poor. Perth: Albatross books.

Hayes, J.B. 2006. Sub-merge. Living deep in a shallow world: Service, justice and contemplation among the world's poor. Ventura: Regal.

Hayes, J. and Penate-Aceves, J. 2010. "Communal" in living mission. In Bessenecker, S.A. (ed.), the vision and voices of new friars. Downers Grove: IVP Books. 
Hendriks, J. 2010. A change of heart - Missional theology and social development. In Swart, I., Rocher, H., Green, S. and Erasmus, J. (eds), Religion and social development in post-Apartheid South Africa. Stellenbosch: Sun Press.

Huckins, J. and Yackley, R. 2012. Thin places. Six postures for creating and practicing missional community. Kansas City, MO: The House Studio.

Katongole, E. 2011. The sacrifice of Africa. A political theology for Africa. Grand Rapids: William B. Eerdmans publishing company.

Kraybill, D.B. 1990. The upside-down kingdom. Rev. ed. Scottdale, Pennsylvania: Herald Press.

Kelsey, D. 2017. Media and affective mythologies: Discourse, archetypes and ideology in contemporary politics. Cham: Palgrave Macmillan.

Metcalf, S.F. 1989. A blueprint for a sodalic order within church resource ministries focusing on the urban poor. Unpublished doctoral dissertation, Fuller Theological Seminary: Pasadena, Southern California.

Metcalf, S.F. 2018. Too great to count. Our journey to the nations. Exploring the influences that shape CRM/Novo. Anaheim: CRM foundations.

Metcalf, S.F. 2019. To the ends of the earth. What are movements of good news? Anaheim: Novo foundations.

Novo. 2020. Vision statement. Available: www.novo.org. Accessed 13 March 2020.

Nyiawung, M.D. and Van Eck, E. 2013. An African hermeneutic reading of Luke 9:1822 in relation to conflict and leadership in pastoral ministry: The Cameroonian context, HTS Teologiese Studies/Theological Studies 69(1), Art. \#1201, 9 pages. Available: http://dx.doi.org/10.4102/ hts.v69i1.1201.

Pali, K.J. 2018. An analysis of conflict situations within the leadership and various structures of the Dutch Reformed Church in Africa, Orange Free State, HTS Teologiese Studies/ Theological Studies 74(2), a4972. Available: https://doi.org/ 10.4102/hts.v74i2.4972.

Oppenshaw, D.L., Nel, M. and Louw, L. 2018. Conflict resolution and reconciliation within congregations, HTS Teologiese Studies/Theological Studies 74(2), a4641. Available: https://doi.org/ 10.4102/hts.v74i2.4641.

Osterhaus, J.P., Jurkowski, J.M. and Hahn, T.A. 2005. Thriving through ministry conflict. Grand Rapids, MI: Zondervan Publishing House.

Perkins, J.M. 1993. Beyond charity. The call to Christian community development. Grand Rapids: Baker Books.

Pillay, J. 2017. The church as a transformation and change agent, HTS Teologiese Studies/Theological Studies 73(3).

Winter, R. 1974. The two structures of God's redemptive mission, Missioloqy: an international review, 2 (1).

Winter, B. 1994. Seek the welfare of the city: Christians as benefactors and citizens. First-century Christians in the Graeco-Roman World. Grand Rapids, MI: Eerdmans. 